\title{
Plano de formação, letramento e práticas educativas na pedagogia da alternância'
}

\author{
Cícero da Silva ${ }^{2}$ \\ ORCID: 0000-0001-6071-6711
}

\section{Resumo}

Com interesse de ampliar as pesquisas enfocando práticas educativas no âmbito da educação do campo, neste artigo, objetivamos analisar e compreender o processo de construção e implementação de um plano de formação nas atividades didático-pedagógicas da Escola Família Agrícola Zé de Deus (EFAZD), situada na área rural do município de Colinas do Tocantins, estado do Tocantins, Brasil. Esse plano integra o sistema educativo da pedagogia da alternância (PA) e é implementado nas escolas que assumem essa pedagogia. A pesquisa é de natureza etnográfica e de abordagem qualitativo-interpretativa nas análises dos dados. Os dados foram gerados em 2014 e são constituídos por trechos (transcritos) de uma entrevista, registros fotográficos de atividades práticas de estudos e reunião na escola, plano de formação de 2014, excertos do projeto político-pedagógico da escola-campo e textos de dois exemplares do gênero caderno da realidade produzidos por dois estudantes colaboradores da pesquisa. Os resultados do estudo mostram que a construção do plano de formação na EFAZD envolveu a comunidade e levou em consideração a realidade local dos estudantes, das famílias e das comunidades camponesas. Portanto, por meio da execução dos temas geradores dos planos de estudo elencados no plano de formação, há um diálogo efetivo na PA com um currículo mais condizente com a realidade do meio rural, uma vez que tais temas estão vinculados diretamente às atividades e à realidade socioprofissional do jovem camponês.

\section{Palavras-chave}

Alternância - Escola do campo - Plano de formação - Ensino - Letramento.

\footnotetext{
1- Esta pesquisa foi realizada no âmbito do projeto "Caderno da Realidade na Pedagogia da Alternância: um instrumento pedagógico mediador do letramento" (Propesq/UFT nº T03\#001/2015) e contribui para as atividades científicas do Grupo de Estudos e Pesquisas em Educação do Campo - Gepec/CNPq.

2- Universidade Federal do Tocantins, Tocantinópolis, T0, Brasil. Contato: cicolinas@yahoo.com.br.
}

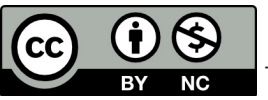




\section{Training plan, literacy, and educational practices in the pedagogy of alternation}

\section{Abstract}

With interest in expanding research focusing on educational practices in rural education, the purpose of this paper is to analyze and understand the process of devising and implementing a training plan in the didactic-pedagogical activities of the Agricultural Family School Zé de Deus (AFSZD), located in the municipality of Colinas do Tocantins, state of Tocantins. This plan integrates the educational system of pedagogy of alternation (PA) and is implemented in schools that utilize this pedagogy. The research is ethnographic and has a qualitative-interpretative approach to data analysis. The data were generated in 2014 and consist of excerpts (transcripts) of an interview, photographic records of practical activities of study, and meeting at school, training plan for the year 2014, excerpts from the political-pedagogical project of the rural school, and copies of the genre notebook of reality produced by two students who cooperated with the study. The research results have revealed that devising the training plan at AFSZD involved the community and took into account the local reality of students, families, and peasant communities. Therefore, by executing the generating themes of the study plans listed in the training plan, there is an effective dialogue in the PA with a curriculum that best aligns with the reality of the rural environment, since such themes are directly linked to the activities and socioprofessional reality of the young peasants.

\section{Keywords}

Alternation - Rural school - Training plan - Teaching - Literacy.

\section{Introdução}

Neste artigo, buscamos analisar e compreender a construção e a implementação de um plano de formação segundo os princípios do sistema educativo da pedagogia da alternância (PA), mais especificamente nas atividades didático-pedagógicas de uma escola situada no meio rural brasileiro. 0 trabalho integra uma pesquisa mais ampla desenvolvida para produção de nossa tese de doutoramento ${ }^{3}$ defendida no Programa de Pós-Graduação em Letras: Ensino de Língua e Literatura da Universidade Federal do Tocantins (PPGL/UFT). Cabe-nos ressaltar que o objetivo principal dessa pesquisa (ampla) é analisar práticas e eventos de letramentos mediados pelos instrumentos pedagógicos da pedagogia da alternância em uma escola família agrícola (EFA) brasileira (SILVA, 2018).

Com base em Street (2014), podemos afirmar que eventos e práticas de letramento não constituem o mesmo elemento, mas andam lado a lado. Isso porque:

3- Registro os meus agradecimentos ao Prof. Dr. Adair Vieira Gonçalves (orientador) e a Profa Dra Luiza Helena Oliveira da Silva (coorientadora) pelas contribuições à pesquisa. 
0 conceito de "práticas de letramento" se coloca num nível mais alto de abstração e se refere igualmente ao comportamento e às conceitualizações sociais e culturais que conferem sentido aos usos da leitura e/ou da escrita. As práticas de letramento incorporam não só os "eventos de letramento", como ocasiões empíricas às quais o letramento é essencial, mas também modelos populares desses eventos e as preconcepções ideológicas que os sustentam. (STREET, 2014, p. 18).

Assim, de acordo com a esfera social de uso da linguagem, serão empreendidos diferentes eventos e práticas de letramento.

Considerando a natureza e o escopo do objeto de investigação, o trabalho está situado no campo aplicado dos estudos da linguagem (MOITA LOPES, 2006), cujas contribuições vêm principalmente de áreas como educação (FREIRE, 2005; GIMONET, 2007; ARROYO, 2013; NOSELLA, 2014) e teorias do letramento (TINOCO, 2008; KLEIMAN, 2014; STREET, 2014). Esse aporte teórico guiará os desdobramentos do enfoque ao objeto de estudo. Também estabelecemos diálogos com os estudos de Mattos (2014), Silva (2018) e Silva e Gonçalves (2018), já que esses autores analisam aspectos do plano de formação no contexto educativo da PA.

0 estudo de campo foi desenvolvido em um período longitudinal em 2014 na Escola Família Agrícola Zé de Deus (EFAZD), situada no município de Colinas do Tocantins, estado do Tocantins, Brasil (SILVA, 2018). A pesquisa é de natureza etnográfica (ANGROSINO, 2009; ANDRÉ, 2012), sendo adotada a abordagem qualitativa e interpretativa na análise dos dados gerados (MASON, 2002; DENZIN; LINCOLN, 2006). Para gerar os dados, contamos com a participação direta e indireta de dezenove estudantes e nove monitores ${ }^{4}$ colaboradores dessa EFA na execução dos oito temas dos planos de estudo (PE), na turma do $1^{\circ}$ ano do curso técnico em agropecuária integrado ao ensino médio.

Os registros da pesquisa (ampla) são: material audiovisual - como gravações das interações em sala de aula e de atividades desenvolvidas pelos estudantes nas comunidades, diários de campo do pesquisador, documentos da escola-campo, registros fotográficos de atividades, espaços e objetos, além de textos de exemplares de gêneros como caderno da realidade e caderno de acompanhamento elaborados pelos estudantes colaboradores da turma envolvida na pesquisa. Contudo, os dados analisados neste artigo são constituídos por trechos (transcritos) de uma entrevista com um monitor registrada na pesquisa, registros fotográficos de atividades práticas de estudos e reunião na escola, plano de formação de 2014, excertos do projeto político-pedagógico da escola-campo e textos de dois exemplares do gênero caderno da realidade produzidos por dois estudantes colaboradores da pesquisa. Justificamos que, devido a este trabalho integrar uma pesquisa bastante grande desenvolvida para produção de nossa tese, tivemos que fazer esse recorte e enfocar apenas atividades vinculadas direta ou indiretamente ao plano de formação e execução de atividades sobre os temas dos PE elencados nesse plano.

Este artigo está organizado em duas partes principais. A primeira traz a introdução e a perspectiva teórica assumida no estudo. Na segunda parte, são apresentados os dados

4- Na alternância, monitor é a denominação que o professor recebe. Nesse contexto educativo, as atribuições de um monitor transcendem as atividades didático-pedagógicas recorrentes em sala de aula, já que esse profissional também assume outras responsabilidades no processo formativo dos estudantes (SILVA, 2018). 
da pesquisa, bem como as análises acerca da construção/implementação do plano de formação nas atividades didático-pedagógicas da escola-campo. Para finalizar, o trabalho traz as considerações a respeito dos resultados do estudo.

\section{A pedagogia da alternância e sua proposta formativa}

A pedagogia da alternância (PA) originou-se em 1935, no interior da França, com a criação das primeiras Maisons Familiales Rurales ${ }^{5}$ (Casas Familiares Rurais). Esse sistema educativo considera diferentes valores e experiências dos estudantes, atribuindo grande valorização à cultura, aos saberes e à realidade socioprofissional de crianças e jovens camponeses nos processos formativos (QUEIROZ, 2004; GIMONET, 2007). Para alcançar isso, muitas atividades escolares desenvolvidas sob a ótica da PA são articuladas a temáticas, às práticas cotidianas e à vida no meio rural, agregando os conhecimentos acumulados pelos estudantes nas suas experiências concretas.

Apesar de ainda ser pouco difundida e explorada nas pesquisas no meio acadêmico, por estar integrada à educação do campo, a alternância desenvolveu e aperfeiçoou nos últimos oitenta anos uma proposta teórico-metodológica própria que congrega escola, família e comunidade nos processos de formação humana. Tal peculiaridade, por si só, requer que concebamos campo como um lugar de vida, saberes, cultura e identidade próprias, reforçando a necessidade de ajustes e integração da escola à vida social dos povos do campo (CALDART, 2002). Nesse entendimento, o espaço social denominado campo para a educação do campo/pedagogia da alternância deixa de ser visto como prolongamento dos limites urbanos, ainda bastante evidente nas bases da escola rural. ${ }^{6}$

É importante ressaltar que, a partir da década de 1990, os povos do campo do Brasil, com apoio dos movimentos sociais, mobilizaram-se e passaram a reivindicar uma modalidade de educação que seja no e do campo. Parafraseando Caldart (2002), no campo justifica-se porque as pessoas têm direito a ser educadas no lugar onde elas vivem e convivem com seus familiares; do campo, pois compreende-se que os povos do campo têm direito a uma educação pensada sob a ótica das demandas da comunidade local e com a sua participação, vinculada à sua cultura, aos saberes e às suas necessidades humanas e sociais.

Nas práticas educativas desenvolvidas sob a perspectiva da PA, procura-se romper com o modelo tradicional de ensino propagado na escola rural, com esse currículo sob o qual até hoje crianças, jovens e adultos camponeses foram educados no sistema formal de ensino. Trata-se de um currículo ${ }^{7}$ que nega suas diferenças, seu território, suas lutas por um espaço de vida e de trabalho, suas crenças, sua cultura, seus saberes, e que os considera

5- No Brasil, as unidades educacionais mais conhecidas e que assumem o sistema educativo da pedagogia da alternância são as escolas famílias agrícolas (EFA) e as casas familiares rurais (CFR). Elas também são denominadas de centros educativos familiares de formação por alternância (CEFFA) (QUEIROZ, 2004).

6- A educação para os povos do campo brasileiros geralmente acontece(u) nas escolas rurais. Esse tipo de escola é marcado, principalmente, pelas más condições de funcionamento, corpo docente sem formação inicial mínima exigida pela legislação, currículo e calendário não condizentes com a realidade dos camponeses, etc. (SILVA, 2018).

7- Para Arroyo (2013), a luta pela construção e o fortalecimento da escola do campo passa pela valorização da cultura, dos saberes, da identidade dos camponeses, bem como pela seleção dos conteúdos. Isso porque as teorias emaranhadas nos conteúdos não são neutras. 
sob o prisma da educação ofertada nas escolas urbanas. Sem dúvidas, a alternância consolida-se no Brasil devido à inoperância do poder público (Estado brasileiro) e à falta de uma política pública educacional séria e eficaz capaz de atender as reais necessidades de formação dos camponeses, que só tem conseguido oferecer uma educação aos povos do campo tomando o homem urbano como referência, a exemplo do currículo e dos materiais didáticos da educação rural.

Desde que a PA foi implantada no Brasil em 1969, com a criação de três EFA pelo Movimento de Educação Promocional do Espírito Santo (MEPES) no estado do Espírito Santo, as experiências educativas fomentadas pela alternância constituem uma referência pedagógica para a formação de crianças, jovens, adultos camponeses e lideranças dos movimentos sociais do campo brasileiro (MOREIRA, 2000; SILVA, 2012 [2003]; CALIARI, 2013; NOSELLA, 2014). Mais recentemente, passou a fundamentar cerca de 44 cursos de graduação específicos para a formação de professores em educação do campo nas diversas áreas do conhecimento vinculados a diferentes instituições públicas de ensino (Universidades Federais e Institutos Federais de Educação, Ciência e Tecnologia) brasileiras. Todos os anos, a rede CEFFA promove a formação de milhares de jovens camponeses brasileiros. Isso é explicado porque, "na ausência de políticas públicas voltadas para a educação do campo, a EFA se tornara uma alternativa quase única de escolarização na maioria das comunidades rurais" (NOSELLA, 2014, p. 262).

A formação promovida pela PA congrega teoria e práxis, experiência e reflexão. Para tanto, são estabelecidos dois tempos e espaços formativos diferentes que se alternam entre escola e família/propriedade, quais sejam: (i) Tempo Escola (TE): referese ao período de aulas realizadas no centro de formação/escola articulado entre estudo, pesquisa e propostas de intervenção; (ii) Tempo Comunidade (TC): trata-se do período de vivência dos estudantes na propriedade/comunidade, pesquisa de estudo, realização de experimentos, trabalho coletivo, entre outras atividades (MOREIRA, 2000; GIMONET, 2007; RIBEIR0, 2008), além de estarem integrados com os instrumentos pedagógicos. ${ }^{8}$ Assim, a alternância cria condições para que as crianças e os jovens oriundos do campo aprendam tanto por meio dos conhecimentos teóricos sistematizados na academia quanto dos saberes vinculados à realidade cotidiana do mundo camponês (ESTEVAM, 2001; QUEIROZ, 2004; GIMONET, 2007).

As experiências formativas em alternância vivenciadas nos CEFFA, ao longo da história do movimento nos diferentes contextos, fomentaram discussões pautando a importância de assumir uma identidade comum para alcançar a unidade do movimento e preservar os ideais originais concebidos pela PA. Segundo Gimonet (2007), a expansão do movimento dos CEFFA pelo mundo, em especial as experiências brasileiras, motivaram certas adaptações no projeto ao longo dos tempos, de modo que os princípios dessa pedagogia passaram a ser representados pelos quatro pilares da pedagogia da alternância conhecidos atualmente, como mostra a Figura 1:

\footnotetext{
8- Para maiores detalhes a respeito dos instrumentos pedagógicos da PA, consultar Estevam (2001), Gimonet (2007) e Silva (2011).
} 
Figura 1 - Os quatro pilares dos CEFFA

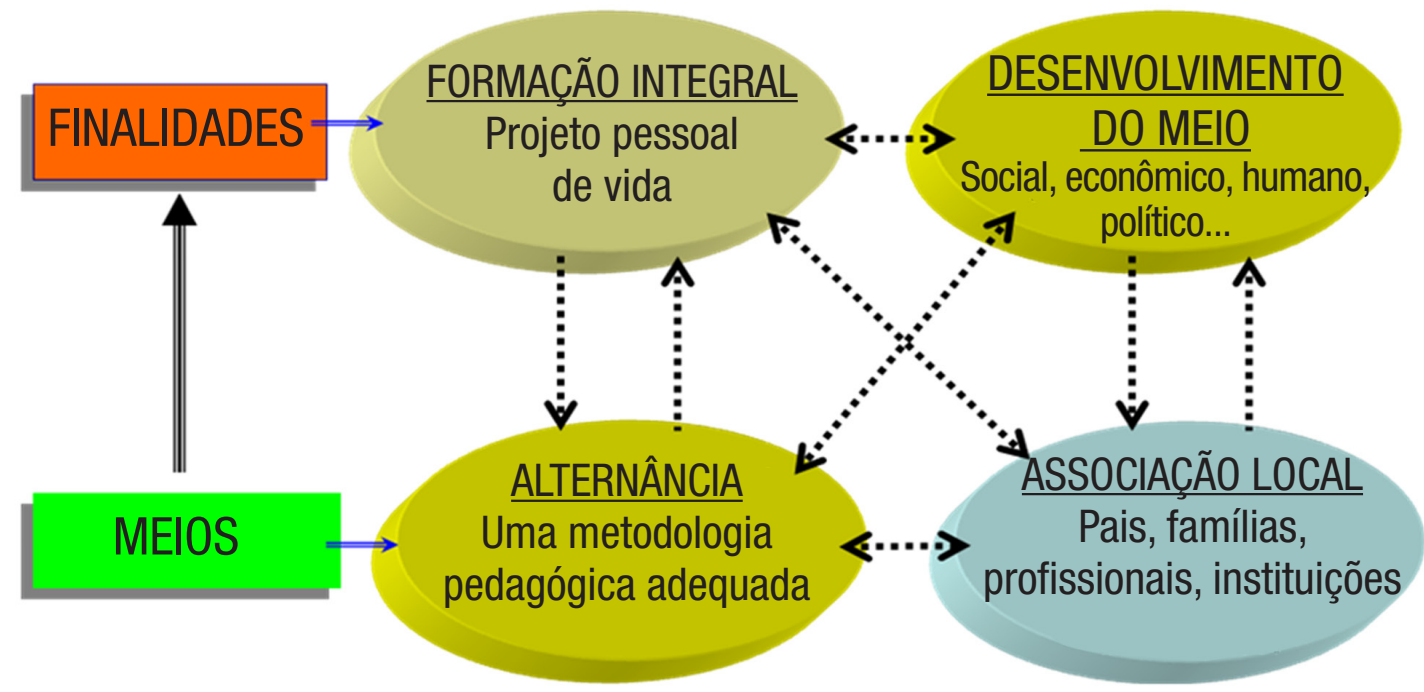

Fonte: adaptado de Garcia-Marirrodriga e Puig-Calvó (2010, p. 66).

Os pilares ilustrados na Figura 1 apresentam os componentes principais de sustentação do movimento dos CEFFA no mundo (GIMONET, 2007). Assim, o objetivo primordial das unidades educativas que adotam a alternância nas práticas de formação é promover o desenvolvimento dos atores sociais e das comunidades em que estão inseridas, a curto, médio e longo prazos, com ênfase na formação de crianças e jovens. Para alcançar tal objetivo, Garcia-Marirrodriga e Puig-Calvó (2010) lembram que são estabelecidas as finalidades (Figura 1) do movimento dos CEFFA, sendo organizadas em dois eixos: formação integral e desenvolvimento do meio ou local. Ao defender esses pilares ou princípios, a alternância nos ensina que sua proposta oferece condições capazes de proporcionar uma formação condizente com a realidade social e econômica de crianças, jovens camponeses e suas famílias.

Além disso, no processo de formação baseado nos princípios da PA, os instrumentos pedagógicos são tomados como mecanismos de ação que possibilitam a interação ativa dos alternantes com os monitores, a família, os parceiros da formação, o ambiente socioprofissional, a cultura e o conhecimento científico. Considerando a rede de parceiros coformadores (GIMONET, 2007), depreendemos que, nesse contexto de ensino, os monitores e os profissionais/técnicos voluntários de entidades parceiras do CEFFA assumem atribuições de agentes de letramento, especialmente na implementação dos diferentes instrumentos pedagógicos. Para Kleiman (2014, p. 88), "o agente de letramento, que pode ser o professor, um voluntário da comunidade, um pesquisador, orienta o trabalho do aluno fornecendo materiais relevantes e modelos de 
atividades significativas”. Nas práticas educativas desenvolvidas na PA, os monitores (e profissionais voluntários) planejam atividades/ações coletivas e delas participam com o grupo de estudantes, interagem com outros monitores, coordenadores, pais e demais atores sociais da comunidade, cujo propósito é fortalecer os instrumentos pedagógicos e ampliar a gama de atividades vinculadas à formação dos aprendizes (estudantes) envolvidos (MOREIRA, 2000).

Evidentemente, é nessas interações que acontece a formação integral (SILVA, 2011). Ou seja, os agentes de letramento e os instrumentos pedagógicos colocam a criança ou o jovem em processo de formação "[...] na função de sujeito da atividade e, consequentemente, da construção do seu próprio conhecimento" (COLINAS, 2015, p. 19). Conforme definido no projeto político-pedagógico da EFAZD, os principais instrumentos pedagógicos da PA adotados nas práticas educativas desse CEFFA são doze, denominados de (1) plano de estudo; (2) colocação em comum; (3) caderno da realidade; (4) visita de estudo; (5) visita à família; (6) projeto profissional do jovem; (7) intervenção externa; (8) atividade de retorno; (9) acompanhamento individual; (10) avaliação semanal; (11) caderno de acompanhamento; e (12) cursos (COLINAS, 2015).

$\mathrm{Na}$ escola-campo, as atividades pedagógicas relacionadas ao conjunto de instrumentos pedagógicos elencados anteriormente são organizadas em quatro grupos: (1) ação no internato; (2) ação na comunidade; (3) ação no(a) internato/comunidade; e (4) ações organizacionais (COLINAS, 2015). Neste artigo, aprofundaremos nas análises discussões somente a respeito do (1) plano de formação e do (2) plano de estudo. Segundo a proposta formativa da alternância, o plano de formação é responsável pela articulação de conteúdos nos aspectos teórico e prático.

\section{O plano de formação na alternância}

0 plano de formação (PF), gestado no decorrer da trajetória histórica das experiências formativas na perspectiva da alternância nos CEFFA, é responsável por favorecer a organização das disciplinas e dos planos de estudo (PE) como estratégia para regular a proposta didático-pedagógica orientada pela PA, tornando também mais controlável o processo de produção do gênero caderno da realidade (SILVA, 2018). Como defendemos em um de nossos estudos, esse plano tem como objetivo “[...] formalizar, organizar, visualizar os conteúdos e as finalidades de uma formação eficaz" (SILVA, 2011, p. 36). É importante enfatizar que o PF é similar a um plano de ação, pois apresenta as finalidades que orientam a missão educativa de um CEFFA, como a autonomia das pessoas, o desenvolvimento do meio socioprofissional (ou comunidade local) e as metas a serem alcançadas pelos jovens. Trata-se, portanto, de um plano que traz os conteúdos do currículo que serão desenvolvidos por estudantes e monitores durante um ano letivo, como mostra o quadro que segue: 
Quadro 1 - Plano de formação ${ }^{9}$ de um CEFFA

\begin{tabular}{|c|c|c|c|c|c|c|c|c|c|c|c|c|c|c|c|c|c|c|c|c|}
\hline \multicolumn{7}{|c|}{ Conhecimento da Realidade } & \multicolumn{5}{|c|}{ Disciplinas Profissionais } & \multicolumn{9}{|c|}{ Disciplinas do Núcleo Comum } \\
\hline 응 & 怘 & 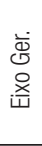 & $\begin{array}{l}\text { Plano de Estudo (PE) } \\
\text { - Tema de Pesquisa no } \\
\text { meio socioprofissional }\end{array}$ & 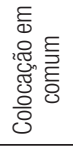 & 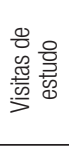 & 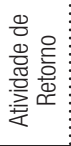 & 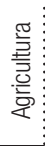 & 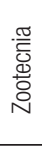 & 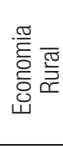 & 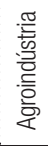 & 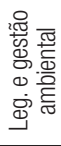 & $\begin{array}{l}\stackrel{\mathscr{d}}{\mathrm{S}} \\
\stackrel{\mathrm{D}}{\mathrm{t}} \\
\stackrel{0}{\circ}\end{array}$ & 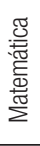 & 萨 & $\begin{array}{l}\frac{\pi}{\pi} \\
\overline{\frac{\pi}{2}} \\
\mathbb{J}\end{array}$ & $\frac{\pi}{0}$ & . & 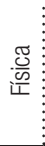 & $\frac{\infty}{\frac{8}{2}}$ & 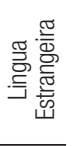 \\
\hline \multirow{8}{*}{$1^{0}$} & 1 & \multirow{8}{*}{ 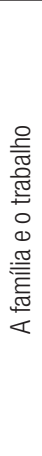 } & $\begin{array}{l}\text { História da minha } \\
\text { família }\end{array}$ & & & & & & & & & & & & & & & & & \\
\hline & 2 & & A divisão do trabalho & & & & & & & & & & & & & & & & & \\
\hline & 3 & & Alimentação animal & & & & & & & & & & & & & & & & & \\
\hline & 4 & & $\begin{array}{l}\text { A propriedade e sua } \\
\text { organização }\end{array}$ & & & & & & & & & & & & & & & & & \\
\hline & 5 & & Agricultura orgânica & & & & & & & & & & & & & & & & & \\
\hline & 6 & & Seleção de sementes & & & & & & & & & & & & & & & & & \\
\hline & 7 & & $\begin{array}{l}\text { Manejo de pragas e } \\
\text { doenças }\end{array}$ & & & & & & & & & & & & & & & & & \\
\hline & 8 & & $\begin{array}{l}\text { Colheita e } \\
\text { armazenagem }\end{array}$ & & & & & & & & & & & & & & & & & \\
\hline
\end{tabular}

Fonte: Silva (2011, p. 37).

Esse exemplo apresentado no Quadro 1 é de um curso técnico agrícola de nível médio. Dependendo do nível de ensino (fundamental ou médio), o tipo de curso e o propósito de formação do CEFFA, o plano de formação pode apresentar diferenças, principalmente em relação aos temas dos PE. Gimonet (2007, p. 70) afirma que "a formação alternada supõe ‘dois programas' de formação: o da vida e o da escola. [...]”. 0 plano engloba as disciplinas do núcleo comum do currículo, tais como português, história, geografia, matemática, biologia, etc. Estas seriam representantes do "programa da formação escolar" (GIMONET, 2007). O PF traz ainda aquelas disciplinas que contemplam "conhecimento da realidade", ou seja, as disciplinas profissionais: agricultura, zootecnia, agroecologia, economia rural, etc., cujo propósito é contribuir para a formação e a preparação dos estudantes para a vida socioprofissional. Por tudo isso, a seleção dos temas geradores dos PE para integrar um plano de formação leva em consideração a realidade local dos estudantes, além de serem definidos anualmente com a participação dos estudantes e de suas famílias. Na pesquisa de Mattos (2014), cujo objetivo foi investigar como acontece a articulação entre temas geradores (ou PE) e conteúdos previstos para o ensino médio, em um CEFFA, a autora afirma que o PF “[...] sistematiza as atividades e os conteúdos - vivenciais, formação geral e formação profissional - no que se refere à sequência das alternâncias e ao conjunto do percurso da formação do jovem" (MATTOS, 2014, p. 97).

Portanto, os temas geradores dos PE, elencados no plano de formação dos CEFFA para cada ano letivo, tornam-se os conteúdos de registros dos CR. Por isso, o CR "[...] é o instrumento de sistematização da reflexão e da ação provocada pelo plano de estudo" (SILVA, 2011, p. 89, grifo nosso). Ou seja, a construção desse gênero pode favorecer a uma preparação do indivíduo de maneira integral, inserido em uma relação dialógica

9- Adaptado por Silva (2011) de Estevam (2001) e Gimonet (2007). 
com diferentes atores sociais na construção de conhecimento na esfera escolar, família e comunidade local, o que também contribui para o letramento.

\section{Construção e implementação do plano de formação na pedagogia da alternância}

0 plano de formação (PF), conforme apresentado na seção anterior, é responsável pela organização das diferentes disciplinas do currículo de um centro educativo familiar de formação por alternância (CEFFA) e dos planos de estudo (PE). Isso porque a proposta de formação para os camponeses instituída pelo sistema educativo da alternância articula "dois programas de formação": o da vida e o da escola (GIMONET, 2007). De acordo com o Quadro 1, de um lado, o plano de formação traz as disciplinas do núcleo comum do currículo, como português, história, geografia, matemática, química, artes, entre outras - representantes do programa curricular oficial escolar -, de outro, apresenta aquelas disciplinas que contemplam temáticas voltadas à preparação dos jovens camponeses para a vida socioprofissional, como agricultura, zootecnia, agroecologia, economia rural, etc., além dos temas geradores dos PE.

Esse conjunto de disciplinas abre espaço para reflexões acerca do plano de formação dos CEFFA e da pedagogia da alternância, cujo propósito é oferecer uma formação mais alinhada à realidade do contexto do campo, concretizando-se como um projeto gestado para atender às reais necessidades dos camponeses (MATTOS, 2014; SILVA, 2018). 0 plano de formação contempla tanto as especificidades em termos de conteúdos inerentes ao currículo oficial escolar quanto as especificidades temáticas e demandas da formação para crianças e jovens camponeses, já que engloba processos de letramentos situados dentro das práticas sociais locais, enfatizando o compromisso da escola e da PA com a comunidade e com seus alunos, um dos princípios estruturantes da educação do campo.

Durante nossa segunda visita ${ }^{10}$ à Escola Família Agrícola Zé de Deus (EFAZD) à época da pesquisa de campo, participamos da reunião da equipe de monitores para planejamento e construção do plano de formação do ano letivo 2014 desse CEFFA, sendo definidos naquele momento os temas dos planos de estudo a serem desenvolvidos nas turmas do ensino médio naquele ano. Minha participação em tal reunião tinha o objetivo de apenas observar e registrar, em diário de campo, os desdobramentos do planejamento, em especial a respeito dos temas geradores dos oito PE e respectivas atividades previstas para composição do plano de formação (ver Anexo 1). Nos nossos registros, consideramos mais relevantes para a pesquisa: a) a equipe de monitores; b) os temas geradores dos PE selecionados para a turma colaboradora da pesquisa e respectivas atividades; c) justificativa para escolha do conjunto de temas, bem como o diálogo deles com a realidade dos jovens atendidos pela escola; d) objetivos do estudo dos PE para formação dos alternantes.

10- Essa visita ocorreu na última semana do mês de janeiro de 2014, durante nossa pesquisa de campo (SILVA, 2018). 
Em nossas interações com o monitor Jonas, ${ }^{11}$ que é zootecnista e foi o responsável pelas atividades relacionadas à execução de três PE com a turma colaboradora da pesquisa em 2014, ele reforça que

[...] os temas dos planos de estudo [PE] são decididos nas reuniões, né?, do conselho, no início do ano. E... normalmente são temas que visam buscar maior interação entre as disciplinas, entre o plano de curso e a realidade [dos estudantes]. Então, a gente [monitores] tenta fazer essa conexão ao máximo. (Entrevista com Jonas, 05/09/2014, às 07h34).

Corroborando a afirmação de Jonas, conforme previsto no projeto políticopedagógico da EFAZD ao tratar das ações organizacionais do processo formativo, a defınição dos temas geradores dos planos de estudo não deve ser uma decisão unilateral da equipe pedagógica do CEFFA, pois

[...] estudantes, monitores, famílias e outros colaboradores, definem temas para estudo durante o ano letivo. Os mesmos serão pesquisados junto às comunidades, relacionados com os conteúdos de forma interdisciplinar, aprofundados e sistematizados pelos estudantes. (COLINAS, 2015, p. 22).

Essa maneira de estabelecer os temas geradores dos PE pela EFA focalizada dialoga, perfeitamente, com o pensamento de Freire (2005). Para esse autor, o tema gerador apresenta relações estreitas com os atores sociais e a realidade do mundo que os cerca. Nesse sentido, o estudo de temas geradores dos PE vincula-se diretamente à realidade da comunidade local, isto é, com a práxis dos atores envolvidos no processo de formação:

[...] a importância do plano de estudo é principalmente fazer com que o aluno vivencie, na prática, o que a gente passa pra ele na teoria, ou seja, a gente [nós: monitor e alunos] formula umas questões pra ele perguntar e visitar um produtor [camponês] que trabalhe com aquela determinada cultura. Então, o que é importante é ele [...] fazer um comparativo entre a teoria e o que é vivenciado na prática. Quando ele [aluno] retorna com essas respostas do produtor, então a gente tenta fazer uma conexão, entre o que foi feito... o que foi visto na teoria, e o que é realmente praticado lá no dia a dia, na realidade do produtor. E assim a gente consegue fazer um filtro e o aluno, acredito que ganha esse conhecimento, porque a gente sabe que nem sempre o que tem na teoria é o que é desenvolvido na prática, né? Que o produtor... principalmente o pequeno produtor, trabalha muito com o conhecimento empírico, né? [...] Então, quando ele [aluno] vem e traz a experiência do produtor e a gente confronta com o que é a literatura, acaba enriquecendo ainda mais o conhecimento do aluno e transformando, [...] melhorando assim o ensino e transformando ele num profissional melhor. (Entrevista com Jonas, 05/09/2014, às 07h34).

Além de explicitar as diferentes etapas de estudo de um plano de estudo na EFAZD e sua contribuição para ampliar o conhecimento dos alternantes, Jonas enfatiza um princípio

11- Por questões éticas, asseguramos o anonimato dos colaboradores (monitores e estudantes) da pesquisa. Para tanto, empregamos pseudônimos que nos possibilitem discerni-los. 
basilar da PA, que é estabelecer uma relação constante entre teoria e práxis na formação. Daí, afloram-se os conhecimentos empírico e científico, pois "Quando ele [aluno] retorna com essas respostas do produtor, então a gente tenta fazer uma conexão, entre o que foi feito... o que foi visto na teoria, e o que é realmente praticado lá no dia a dia, na realidade do produtor" (Entrevista com Jonas, 05/09/2014, às 07h34). Nessa perspectiva, os jovens em formação são submetidos a experiências que lhes permitem conhecer e experimentar tanto os conhecimentos locais da comunidade camponesa quanto o que a literatura especializada dispõe sobre determinado tema, como as técnicas de produção de certas variedades de alimentos no campo, conforme apresentam as imagens a seguir:

Figura 2 - Visita de estudo - PE agricultura familiar*

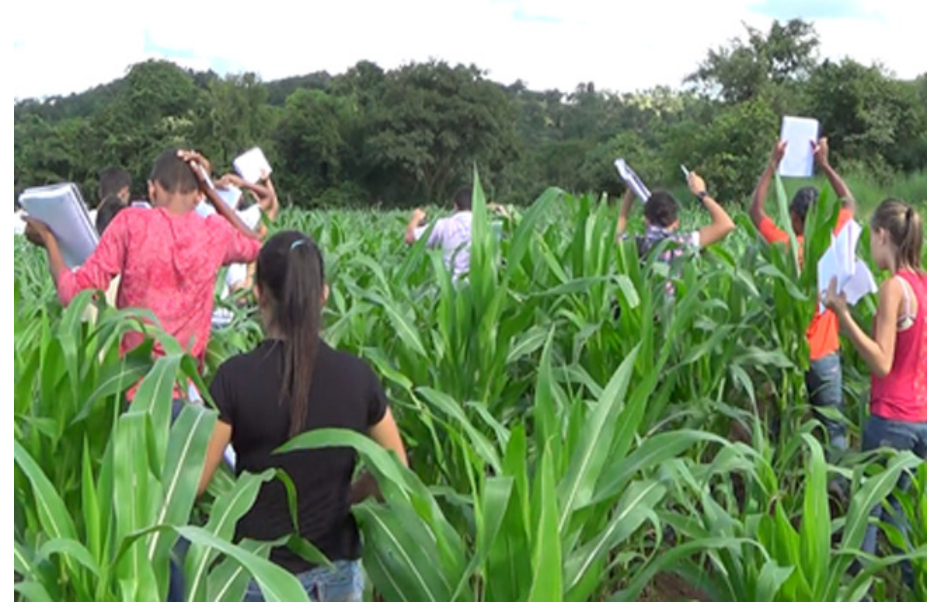

${ }^{*}$ A foto retrata a visita de estudo relacionada à agenda de atividades de estudo do tema do PE agricultura familiar, previsto no plano de formação (Anexo 1).

Fonte: dados da pesquisa (2014).

Figura 3 - Visita de estudo - PE olericultura*

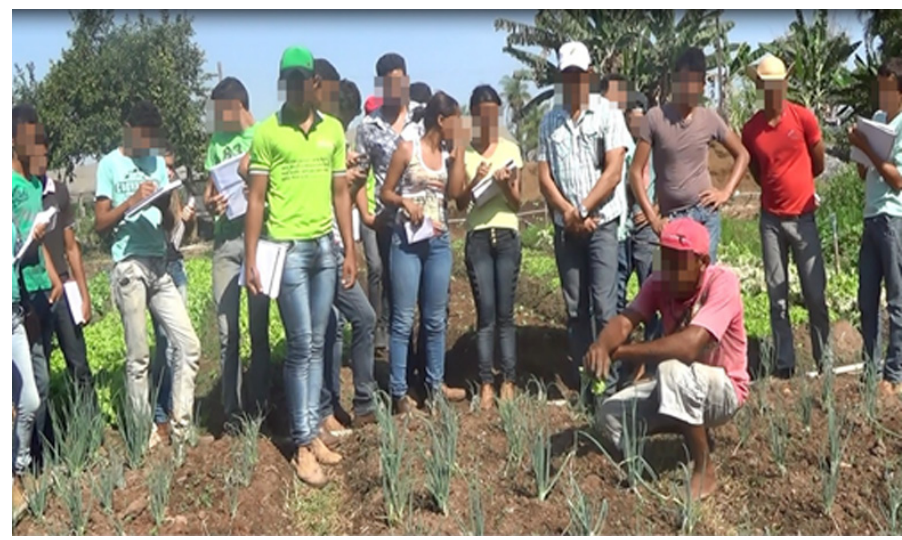

* Esta imagem registra outra visita de estudo dos alternantes a uma horta para ampliar os conhecimentos sobre o tema do PE olericultura. Fonte: dados da pesquisa (2014). 
A Figura 2, por exemplo, retrata o momento da visita de estudo em que os estudantes colaboradores da pesquisa estão conhecendo uma plantação de milho de um agricultor familiar que possui uma pequena propriedade situada em um projeto de assentamento do Instituto Nacional de Colonização e Reforma Agrária (INCRA) no município de Colinas do Tocantins, estado do Tocantins, Brasil. Na imagem, é possível ver os cadernos nas mãos de cada um dos jovens, com a finalidade de tomar nota durante interações orais a respeito da experiência sobre o tema do PE agricultura familiar.

Quanto à visita de estudo sobre o tema do PE olericultura registrada na Figura 3, para ampliar e detalhar as informações do evento, também narro no diário de campo de pesquisa a atividade, como mostra o Exemplo 1:

\section{Exemplo 1 - Visita de estudo}

Assim que monitores e discentes chegaram à horta, foram recebidos pelo funcionário Sr. José, que há oito anos trabalha nessa atividade. Para iniciar a conversa, os alunos (de posse de caderno e caneta para efetuar registros da atividade) perguntaram ao olericultor o tipo e origem do adubo utilizado na horta, o qual explicou que é orgânico (esterco de gado coletado em fazendas).

Em seguida, o Sr. José explicou o processo de cultivo e produção da cebolinha, tempo e técnica de irrigação com aspersor. Por sua vez, os alunos também questionaram sobre custo/benefício da irrigação com o uso de aspersor. Complementando, o monitor Nilson perguntou acerca de valores investidos no sistema de irrigação da hora. Além de dizer que o custo não é baixo, o olericultor também falou sobre a rede de distribuição de água nos canteiros. Dando sequência, o monitor Eduardo procurou quais eram as pragas mais comuns na horta. Por sua vez, o olericultor disse que o caramujo africano era o que mais atacava suas plantas, mas que utilizava iscas para controlá-lo.

Além disso, Sr. José explicou aos alunos que a produção da horta é vendida em feiras e supermercados da região e que as verduras que sobram (descartadas) podem ser usadas como cobertura em canteiros da própria horta. Em seguida, o monitor Nilson questionou Sr. José sobre a origem das sementes utilizadas na horta e o olericultor disse que as sementes são adquiridas em Colinas; ou seja, eles ainda não produzem semente. A estudante Ana perguntou como eram as relações de trabalho e salário dos funcionários da horta. Sr. José disse que trabalha na horta há oito anos e tem carteira de trabalho assinada. Ao todo, são 14 pessoas que ali trabalham.

Uma atividade como essa dificilmente acontece nas escolas. Porém, ela é muito importante para formação dos estudantes por ser mediada por outros eventos de letramento, já que permite conhecer de fato como é a atividade (no caso do $1^{\circ}$ ano: PE Olericultura), como funciona, técnicas utilizadas, produção, adubação, controle de pragas, irrigação, etc., além das interações envolverem oralidade e escrita. (PE Olericultura: Visita de estudo. Diário de Campo. N. 020/2014).

0 excerto do diário de campo do pesquisador apresentado no Exemplo 1 e as Figuras 2 e 3, além de ilustrarem um tipo de evento de letramento peculiar e bastante recorrente nos CEFFA - que inclui a inserção dos estudantes em situações de usos da linguagem (oral e escrita) com a participação de atores sociais da comunidade local -, sinalizam que a PA apresenta uma perspectiva teórico-metodológica capaz de potencializar um tensionamento 
entre teoria e prática a partir das atividades vinculadas aos temas geradores dos PE, os quais ocupam lugar central no processo formativo. Além disso, essa opção metodológica guiada pelos princípios da alternância possibilita a aproximação entre os conhecimentos científicos e populares dentro do sistema formal de ensino, fortalecendo as práticas sociais locais. Portanto, o tema gerador do PE representa a principal peça nessa engrenagem didático-pedagógica específica e recorrente nos CEFFA, contribuindo também para a ampliação do currículo.

Para Caliari (2013, p. 418), enquanto tema gerador, “o Plano de Estudo revestese, pois, de alto significado para o alternante, que passa, a partir dele, a interagir com temáticas relativas ao seu mundo e que são alvo dos seus questionamentos do dia a dia e também de seus familiares”. Os estudos de temas geradores dos PE permitem não só aos estudantes participarem de diferentes práticas sociais de uso da linguagem, como entrevistar, tomar notas, elaborar relatos das experiências nos cadernos, mas também visualizar e compreender o significado político-social de tais conteúdos para a formação (SILVA; GONÇALVES, 2018).

É importante ressaltarmos que a seleção dos temas dos PE para o plano de formação da turma colaboradora de nossa pesquisa (e demais turmas da escola-campo), conforme estabelecem os princípios da alternância, levou em consideração o perfil dos estudantes, a realidade local das famílias e das comunidades. Embora em tal reunião estivessem presentes apenas monitores e a coordenadora pedagógica da escola-campo, a equipe informou que a escolha de cada um dos temas dos oito PE foi baseada em um levantamento de temas de interesse da comunidade, além de visitas prévias às famílias realizadas em janeiro de 2014, pelos monitores, para identificar quais temas seriam de maior interesse e mais importantes para ampliar a formação dos jovens camponeses na EFAZD. Portanto, o diagnóstico junto às famílias configurou-se como uma ferramenta importante para ajudar a equipe a definir os oito temas geradores dos PE para compor o plano de formação.

Com base em tal levantamento junto às famílias e nos diferentes tipos de atividades produtivas desenvolvidas no campo, foram selecionados os temas: agricultura familiar; solo; jardinagem e paisagismo; criação de aves; olericultura; piscicultura; apicultura; e agroextrativismo (Quadro 2), pois representam aquelas atividades mais recorrentes nas comunidades em que circunscrevem a escola-campo. Por sua vez, a equipe pedagógica da EFAZD, aqui representada pela coordenadora pedagógica e os monitores, foi responsável pelo planejamento do plano de formação, pela organização e pela distribuição das atividades relacionadas à execução de cada uma das etapas de estudo dos PE durante o ano letivo, conforme o Anexo 1.

Nessa ocasião, ocorreram discussões a respeito das temáticas sugeridas previamente pelas famílias. Após análise de cada um dos temas geradores, sua relação com as atividades produtivas vinculadas ao campo, importância do conhecimento de tais temas para a formação dos jovens (filhos dos camponeses), objetivos a serem alcançados, demandas relacionadas à logística (locais/propriedade para visitas de estudo, transporte, materiais, etc.) para desenvolver as atividades vinculadas ao estudo dos PE, foram definidos os seguintes temas dos PE para a turma do $1^{\circ}$ ano do ensino médio da EFAZD em 2014: 
Quadro 2 - Síntese do escopo dos temas dos PE

\begin{tabular}{|c|c|c|}
\hline N. & $\begin{array}{c}\text { Tema } \\
\text { gerador/PE }\end{array}$ & Justificativa e relação do tema com a comunidade local \\
\hline 01 & 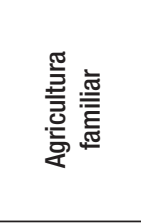 & $\begin{array}{l}\text { Na região de Colinas do Tocantins-TO atendida pela EFAZD, boa parte da população vive no meio rural em pequenas e médias } \\
\text { propriedades e lotes em projetos de assentamentos do INCRA. Portanto, o estudo desse tema justificou-se porque os filhos } \\
\text { dos camponeses precisam conhecer o que é a agricultura familiar, sua importância social e econômica para a comunidade, } \\
\text { participação das famílias no processo de produção, principais produtos cultivados, plantio experimental na escola-campo, } \\
\text { potencialidades, linhas de financiamento, programas governamentais de aquisição de alimentos da agricultura familiar, etc. } \\
\text { Dentre as atividades previstas, está uma visita com a turma a uma propriedade que pratica a agricultura familiar. }\end{array}$ \\
\hline 02 & 응 & $\begin{array}{l}\text { A utilização do solo, seja para o cultivo de alimentos ou para pastagens, se conduzida de maneira não apropriada, pode } \\
\text { gerar problemas ambientais, como erosões (agravadas pelo desmatamento e queimadas descontrolados). } 0 \text { objetivo da } \\
\text { proposta de estudo do tema é ajudar os jovens a adquirirem conhecimentos sobre os tipos de solo, composição, manejo } \\
\text { e conservação, correção para plantio, em especial os da região em que vivem. Além disso, o estudo do tema tinha ainda } \\
\text { como meta levar os estudantes a conhecerem melhor o tipo de solo da propriedade/comunidade em que vivem. }\end{array}$ \\
\hline 03 & 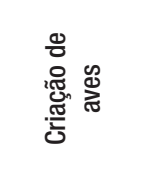 & $\begin{array}{l}\text { A criação de aves em pequenas quantidades, principalmente de galinha caipira, é uma atividade muito comum nas propriedades/ } \\
\text { comunidades da região de Colinas do Tocantins. Por isso, além de conhecer técnicas capazes de ajudar a melhorar o manejo, } \\
\text { alimentação, produção desse tipo de animal e comercialização da produção excedente, a proposição do tema se justificou } \\
\text { também por criar condições para que os jovens pudessem conhecer a produção de aves em grande escala, como ocorre em } \\
\text { granjas. Uma das atividades previstas no estudo do tema é levar os alternantes a conhecerem uma granja de aves. }\end{array}$ \\
\hline 04 & 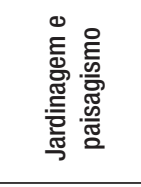 & $\begin{array}{l}\text { Por mais que seja um tema com uma vocação econômica ainda limitada na região que circunscreve a EFAZD, o estudo do } \\
\text { tema é importante porque os jardins (pequenos ou grandes) estão presentes em nossos lares e ajudam a transformar a } \\
\text { paisagem do ambiente. Além disso, criou oportunidade para que os estudantes pudessem melhorar as técnicas de plantio, } \\
\text { adubação, poda das plantas, etc. Dentre as atividades práticas elencadas, está a visita a uma floricultura da cidade pela } \\
\text { turma e participação dos estudantes na (re)construção do jardim da própria escola. }\end{array}$ \\
\hline 05 & 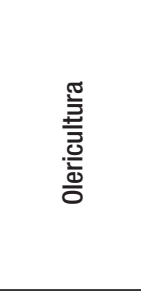 & $\begin{array}{l}\text { A olericultura é uma atividade bastante importante para as famílias da região. Além de produzirem hortaliças (alface, jiló, } \\
\text { couve, coentro, salsinha, cebolinha, pepino, tomate, quiabo, abobrinha, etc.) para o consumo, o excedente da produção é } \\
\text { comercializado em feiras e mercados pelos camponeses. Portanto, o estudo do tema foi escolhido por ajudar os estudantes } \\
\text { a se apropriarem de conhecimentos sobre a importância das hortaliças na alimentação, técnicas para melhorar o cultivo, } \\
\text { comercialização da produção e potencial comercial dos produtos. As atividades práticas envolvem visita a uma grande } \\
\text { horta de Colinas do Tocantins e realização de experimentos na própria horta da EFAZD. } 0 \text { trabalho com o tema desse PE } \\
\text { também objetiva ajudar os alternantes a melhorar ou construir hortas nas propriedades em que vivem, melhorando assim } \\
\text { a alimentação e a renda das famílias. }\end{array}$ \\
\hline 06 & 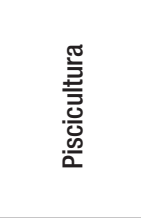 & $\begin{array}{l}\text { A criação de peixes, além de não exigir grandes extensões de terra para instalação de tanques, é uma atividade que está } \\
\text { em expansão na região em que a EFAZD está situada. Basta que a propriedade tenha água para construção de tanques. A } \\
\text { escolha desse tema para estudo justificou-se ainda porque os estudantes precisam conhecer a importância do consumo de } \\
\text { peixe para nossa saúde, técnicas empregadas na piscicultura, áreas apropriadas para instalação de tanques e vantagens } \\
\text { desse tipo de atividade para os pequenos agricultores. } 0 \text { estudo do tema inclui uma visita da turma a uma propriedade para } \\
\text { conhecer a realidade da piscicultura, bem como as espécies de peixes produzidas. }\end{array}$ \\
\hline 07 & 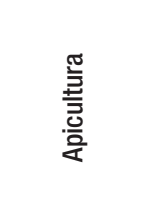 & $\begin{array}{l}\text { Desde o final da década de 1990, a produção de mel vem crescendo em Colinas do Tocantins e região. Prova disso é } \\
\text { que já existe até uma associação dos apicultores sediada na cidade. Ao propor o estudo desse tema, o objetivo é ajudar } \\
\text { os jovens a conhecerem técnicas de criação de abelhas, espécies, extração do mel, importância do mel para saúde e } \\
\text { comercialização dos produtos. } 0 \text { estudo também visa mostrar aos alternantes que, ao lado de outras, a apicultura é uma } \\
\text { atividade apropriada para pequenas propriedades e bastante lucrativa. Uma das atividades práticas é oportunizar que os } \\
\text { jovens conheçam um apiário instalado na área da escola-campo. }\end{array}$ \\
\hline 08 & 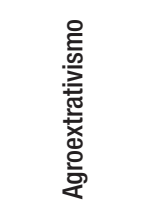 & $\begin{array}{l}\text { Embora as famílias desenvolvam outras atividades em suas propriedades, é recorrente em Colinas do Tocantins e região o } \\
\text { agroextrativismo. Os frutos do cerrado mais coletados (em grande quantidade) na região são: pequi, buriti, murici, cajá e bacaba. } \\
\text { As famílias coletam esses frutos tanto para o consumo próprio quanto para comercialização do excedente in natura e seus } \\
\text { derivados (conservas, polpas e doces). } 0 \text { estudo do tema objetiva mostrar a importância econômica desses produtos para os } \\
\text { pequenos agricultores e o papel da preservação da natureza para garantir a continuidade da produção, já que o desmatamento } \\
\text { e as queimadas estão destruindo o bioma da região, que é o cerrado. }\end{array}$ \\
\hline
\end{tabular}

Fonte: dados da pesquisa (2014). 
A sintese que justifica a escolha de cada um dos temas apresentados no Quadro 2 reforça que a reunião em que se definiu o plano de formação (Anexo 1) é um evento de fundamental importância promovido pela escola-campo e que é mediado pelo diálogo e pelo debate, direta ou indiretamente, entre monitores, pais e estudantes. Além das interações orais ocorridas entre os participantes no planejamento, também foram produzidos esboços, cronograma e o próprio plano de formação com todas as informações a respeito da execução dos PE. As justificativas, por exemplo, e as atividades previstas reforçam que os temas geradores escolhidos estão articulados diretamente ao contexto social e às práticas produtivas da comunidade atendida pela escola. Desse modo, os estudos dos PE propostos podem ser vistos como espaços propícios para debates sobre temas que podem ser relacionados aos problemas da comunidade, como, por exemplo, ajudar os camponeses a aperfeiçoarem as técnicas de manejo dos apiários para aumentar a produção de mel, a conhecerem a importância do consumo de verduras para melhorar a saúde, etc. Isso seria totalmente possível durante a execução dos temas apicultura e olericultura, além desses temas dos PE favorecerem a articulação entre escola, campo e sociedade, algo fundamental na formação dos alternantes.

Ademais, podemos afırmar que a proposta de estudos dos PE mostra a força dos princípios da PA na trajetória de um CEFFA e a importância da formação proposta a ser desenvolvida concomitantemente com os estudos das disciplinas do currículo oficial escolar para os filhos dos camponeses. Isto é, além de estudarem os conteúdos previstos nas disciplinas do currículo tradicional (Quadro 1), nessa EFA, os jovens também estudam temas específicos e realizam atividades práticas/experimentais (Anexo 1) que estão vinculados diretamente à realidade do mundo em que estão inseridos. A seleção dos temas geradores dos PE levou em consideração as demandas e as práticas sociais locais, já que foi uma decisão tomada pela equipe pedagógica com a participação, mesmo que indireta, de outros atores sociais (pais e estudantes) envolvidos no processo de formação. Ou seja, a comunidade foi ouvida previamente pela escola-campo. Como reforça Gimonet (2007, p. 35),

Elaborar o conteúdo do plano de estudo é provocar o intercâmbio no meio do grupo, deixar que as práticas sejam expressas, as experiências, os conhecimentos, as interrogações dos alternantes a respeito do tema. É convidá-los a procurar "o porquê e o como" das coisas, as circunstâncias das ações e sua razão de ser. É ainda levá-los a avaliarem, a darem seu ponto de vista como atores socioprofissionais.

Como sugere o excerto, uma característica muito significativa do sistema educativo da pedagogia da alternância, e que os CEFFA devem levar em consideração por ocasião da elaboração/seleção dos temas dos PE, é convidar e dialogar com a comunidade, ou seja, discutir com ela não só os problemas que a escola enfrenta, mas também debater aqueles temas (especialmente os PE) de que os filhos dos camponeses realmente necessitam para ampliar e melhorar a formação. Vale ressaltar que esse tipo de unidade educativa não mira, por exemplo, apenas o aprendizado ou o aprimoramento das capacidades de leitura e de escrita dos estudantes atendidos; é bem mais que isso. Além disso, as famílias participam da caminhada dos filhos na EFA ruma à formação, como mostra a Figura 4: 
Figura 4 - Reunião com pais, alunos e equipe pedagógica na EFAZD

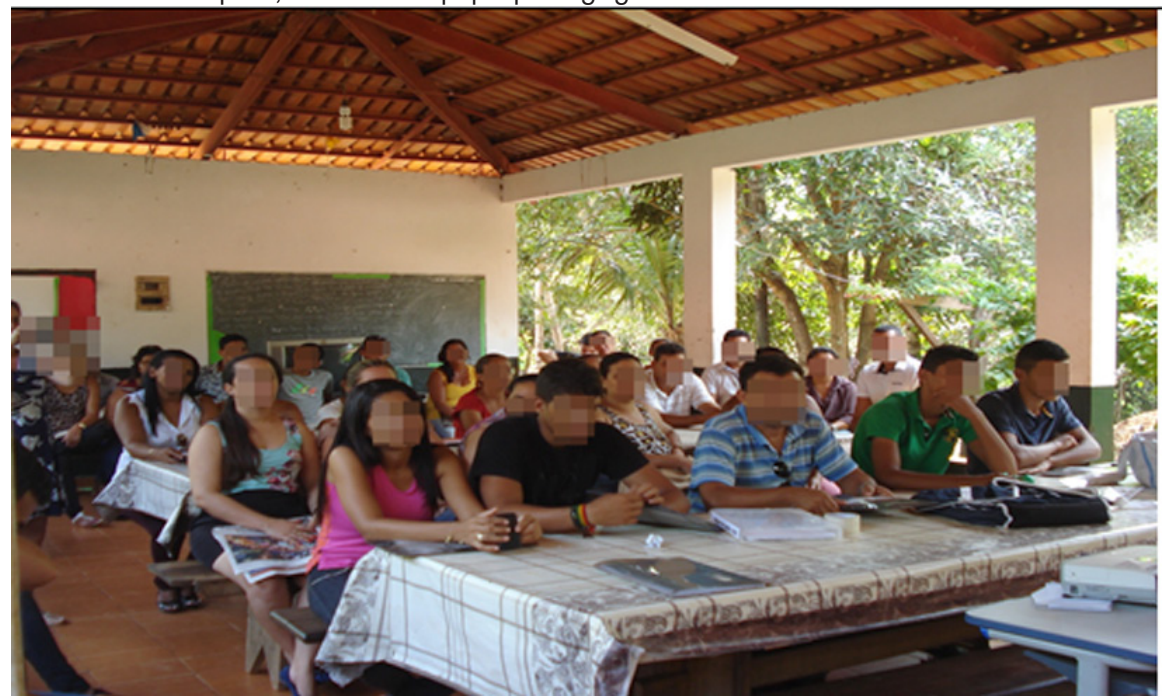

Fonte: dados da pesquisa (2014).

A abordagem realizada acerca da construção do plano de formação também reforça que há uma relação muito estreita entre as práticas educativas recorrentes no contexto de ensino da pedagogia da alternância e os projetos de letramento. Segundo Kleiman e Santos (2014, p. 194),

Os projetos de letramento fornecem um meio de instrumentalizar o professor para as novas funções a serem exercidas: esses projetos se organizam conforme as demandas das práticas sociais que são significativas para a vida acadêmica e profissional, no caso do professor, e para a vida social no local, no caso dos alunos.

Por um lado, esse tipo de projeto permite focalizar a leitura e a escrita de modo que seja possível visualizar os usos sociais da escrita na escola e em outras esferas sociais, bem como o papel sociopolítico da escola junto a outras esferas ou instituições sociais (TINOCO, 2008). Por outro lado, ao ser concebido como "um meio de instrumentalizar o professor" (KLEIMAN; SANTOS, 2014, p. 194), depreendemos que os projetos de letramento também estão entrelaçados ao letramento do professor. Ademais, a construção desse tipo de projeto deve incorporar uma visão político-educativa frente a um problema que emerge na escola/comunidade.

No caso da proposta de construção do plano de formação na EFAZD a partir do conjunto de temas dos PE ilustrados no Quadro 2, de certo modo eles foram escolhidos com a participação da comunidade e dos estudantes porque abarcam demandas/problemas locais, que podem estar relacionados diretamente com a necessidade de preparar os estudantes para ajudar, por exemplo, a melhorar as técnicas de criação de aves, de peixes (piscicultura), de abelhas (apicultura) e produção de verduras (olericultura). Além de envolver a equipe de monitores nas atividades e ações para construção de saberes, valoriza a função políticosocial do CEFFA, reforçando sua aproximação com o propósito de um projeto de letramento. 
A seguir, apresentamos o texto "Colocação em comum” (Figura 5) sobre o tema do PE agricultura familiar (Quadro 2) e que integra o CR produzido pelo colaborador Leomar, um dos estudantes da turma do $1^{\circ}$ ano do ensino médio da escola-campo em 2014:

Figura 5 - Colocação em comum - Registro no CR

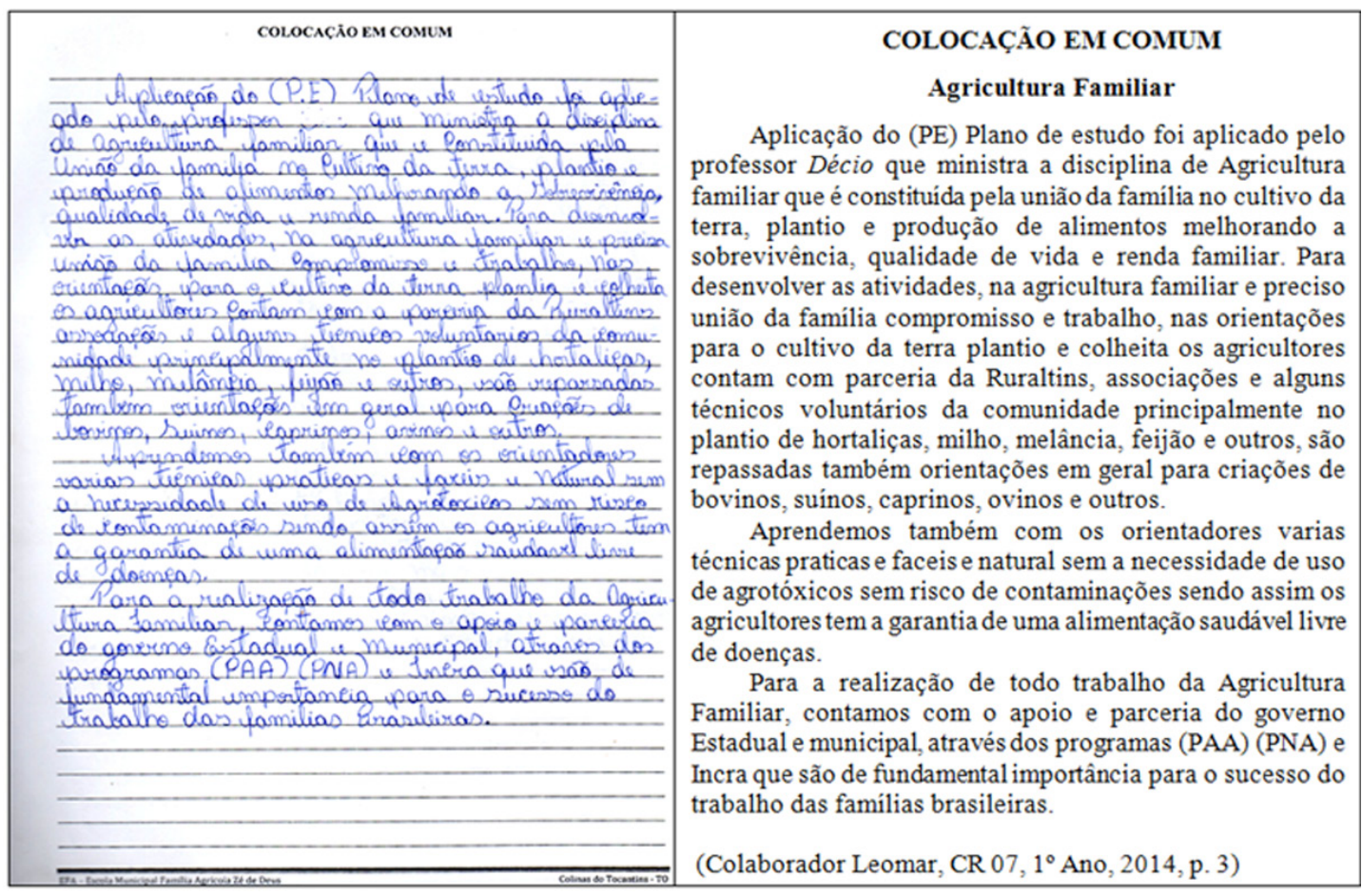

Fonte: dados da pesquisa (2014).

Na alternância, a colocação em comum existe tanto na modalidade oral quanto na modalidade escrita e é caracterizada como uma atividade de socialização de resultados de pesquisas sobre os PE ou de experiências. Em relação ao texto da Figura 5, trata-se de um registro no CR do estudante no qual se apresenta uma espécie de pequeno relato baseado na pesquisa realizada na comunidade sobre o tema do PE agricultura familiar. Assim, "seu objetivo é intermediar a socialização, na modalidade escrita da língua no CR, da experiência e das informações coletadas sobre o tema (do PE) estudado" (SILVA; ANDRADE; MOREIRA, 2015, p. 365).

Por um lado, do ponto de vista do letramento escolar, o texto da Figura 5 é uma produção escrita que demanda revisões, intervenções colaborativas do monitor (formador), uma vez que tais inadequações dizem respeito ao uso da língua na modalidade escrita. Logo, elas poderiam ser solucionadas com a adoção da reescrita por parte do monitor (formador) responsável pelas orientações do aluno na produção do CR. Por outro lado, Leomar foi capaz de sintetizar no texto pontos relevantes sobre os estudos do PE agricultura 
familiar, corroborando o papel sócio-político do CEFFA na sua formação, ao destacar: (i) a importância da união e trabalho da família no cultivo da terra; (ii) a importância da produção de alimentos para melhorar a qualidade de vida e a renda da família camponesa; (iii) o papel da assistência técnica por parte de órgãos como Ruraltins, associações e técnicos voluntários da comunidade visando a melhorar o cultivo da terra e a produção dos agricultores; (iv) a relevância do aprendizado de técnicas naturais de controle de insetos/pragas, evitando assim o uso de agrotóxicos (produtos que trazem risco de contaminações do meio ambiente e dos agricultores); (v) a produção de alimentos saudáveis e livres de contaminação; (vi) o papel do conhecimento de programas como PAA e PNAE do Governo que garantem a aquisição de alimentos produzidos pelas famílias dos pequenos agricultores (SILVA; GONÇALVES, 2018). 0 conjunto de atividades que resultou no texto da Figura 5 nos permite afirmar também que a execução de um plano de formação mobiliza diferentes práticas e eventos de letramento, sendo um tipo de plano semelhante a um projeto letramento, o qual surge da necessidade de envolver professores e alunos em ação para construção de saberes, valorizando a função político-social da unidade educativa (TINOCO, 2008).

Vale destacar que, nos projetos de letramento (TINOCO, 2008), as demandas das práticas sociais se tornam significativas tanto para a vida profissional e acadêmica do professor quanto para a vida social e local dos estudantes. Na PA, o monitor (professor formador) precisa ter disposição, sensibilidade e compromisso social para que possa assumir as atribuições que lhes são conferidas nas atividades dos CEFFA para mediar o processo de formação dos jovens camponeses. E tais exigências conferem a esse formador os mesmos papéis atribuídos aos professores engajados nas ações de um projeto de letramento, entre outras específicas da PA.

Na sequência, a Figura 6 mostra a realização da colocação em comum em que três estudantes redatores convidados pelo monitor Décio são responsáveis por tomar nota, sintetizar o que havia de comum entre as informações coletadas nas pesquisas realizadas nas comunidades sobre o tema do PE agricultura familiar pela turma. Ou seja, criou-se oportunidade para que o espaço do professor na sala de aula do CEFFA fosse ocupado pelos estudantes:

Figura 6 - Colocação em comum - didatização*

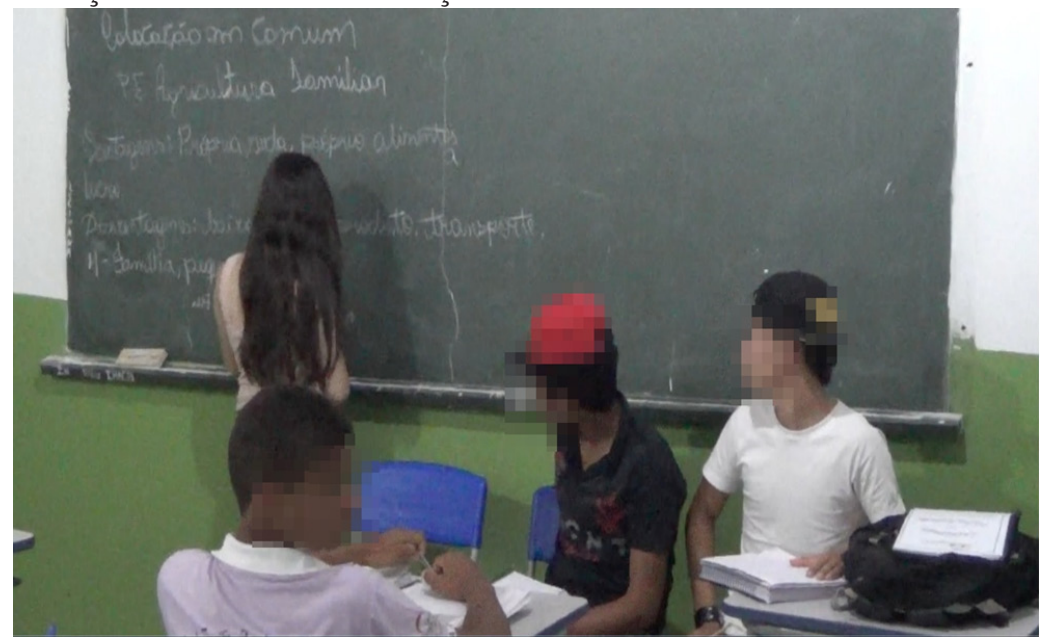

Fonte: dados da pesquisa (2014).

* A foto mostra os estudantes responsáveis pelas atividades relacionadas à colocação em comum, em sala de aula. A colaboradora Nelma assumiu o papel de fazer os registros na lousa, como mostra a Figura 6. 
Como ilustra a Figura 6, a etapa colocação em comum do PE caracteriza-se como um evento de letramento muito recorrente na alternância e bastante significativa para a formação dos jovens. Ela possibilita, principalmente, criar condições para que os jovens em formação possam discutir, sistematizar, dialogar o próprio saber na práxis. Didatizações dessa natureza fertilizam as atividades alicerçadas na perspectiva da PA. Os três estudantes que conduziram as atividades com apoio do monitor, além de terem registrado previamente a colocação em comum na modalidade escrita da língua materna em seção específica do CR, usaram a oralidade para expor ou socializar os resultados de suas pesquisas, o que representa um evento de letramento de fundamental importância em sala de aula capaz de ajudar o aluno a melhorar a expressão oral.

Depreende-se também que, no processo formativo dos CEFFA, o estudante precisa ser capaz de superar a condição de mero espectador na construção do conhecimento, já que as práticas e eventos de letramento dos quais participa exigem engajamento em diferentes atividades mediadas por interações orais e escritas em torno dos temas geradores dos PE e construção do CR. Em outras palavras, assim como nos projetos de letramento, por exemplo, a didatização dos objetos de ensino na alternância relacionada às atividades sobre os temas geradores dos PE de um plano de formação visa ao letramento dos aprendizes.

Na sequência, o texto da Figura 7 traz o registro do CR da estudante Nelma sobre uma visita de estudo referente ao PE jardinagem e paisagismo, realizada pela turma colaboradora da nossa pesquisa a uma floricultura:

Figura 7 - Visita de estudo - PE jardinagem e paisagismo - Registro no CR

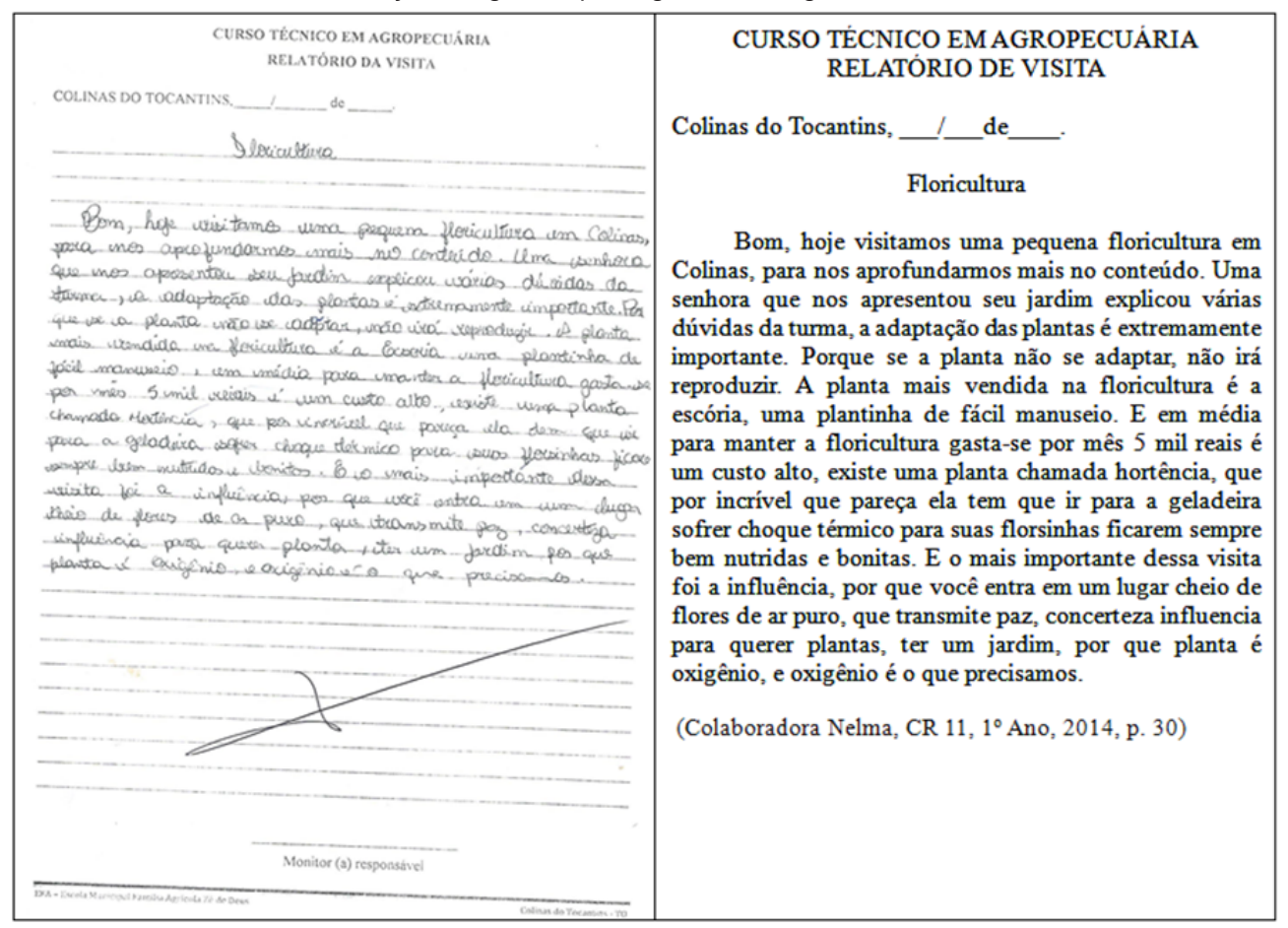

Fonte: dados da pesquisa (2014) 
Na alternância, a visita de estudo é uma atividade que ocorre com o deslocamento de uma turma de estudantes, guiados por um monitor do CEFFA, para visitar e conhecer uma experiência concreta (extraescola) na comunidade e que seja vinculada ao tema de um PE do plano de formação. 0 monitor responsável pela visita prepara, previamente, um roteiro da atividade, a fim de orientar os estudantes a aprofundarem os conhecimentos a respeito do tema de um $\mathrm{PE}$ em estudo e comparar às práticas e conhecimentos individuais (SILVA, 2011). Trata-se de um tipo de atividade que reforça que a alternância oferece a possibilidade de os jovens se apropriarem de saberes não só por meio da teoria, mas especialmente pela práxis.

Além disso, o desenvolvimento das atividades de estudo dos temas geradores dos PE em um CEFFA, por exemplo, como mostra o texto da Figura 7, corrobora que a formação dos estudantes na PA possibilita desenvolver capacidades de linguagem a partir dos usos sociais da escrita na escola e na comunidade. E os registros decorrentes dos estudos ao longo do ano letivo dos oito temas geradores dos PE representam uma das contribuições mais significativas envolvendo capacidades de uso da linguagem, evidenciando também que nos estudos dos $\mathrm{PE}$ os estudantes são levados a produzir alguns gêneros discursivos específicos, como pesquisa do PE, colocação em comum, síntese do PE: minha realidade, intervenção externa, visita de estudo e conclusão e avaliação do PE que integram o caderno da realidade (SILVA; ANDRADE; MOREIRA, 2015; SILVA; GONÇALVES, 2018). Por sua vez, o monitor é o responsável por acompanhar e orientar cada um dos estudantes na elaboração dos registros.

Assim como nos projetos de letramento, essa pedagogia instiga o monitor a exercer novas atribuições no fazer pedagógico, transcendendo os limites das quatro paredes da sala de aula (SILVA, 2018). Conforme apresentado anteriormente, o plano de formação não surge apenas da necessidade de envolver a equipe de monitores e estudantes em uma ação coletiva e colaborativa para construção de saberes sobre determinados temas geradores específicos simplesmente por estarem vinculados à realidade da comunidade local; por trás desse aspecto, tal como nos projetos de letramento, há mecanismos presentes desde a etapa de planejamento até a execução final dos PE capazes de instrumentalizar o docente, fortalecer o letramento do professor, valorizar a função político-social da unidade educativa e valorizar as práticas sociais da comunidade atendida pela escola. Todas as atividades exigem compromisso social e político do monitor com a proposta formativa do CEFFA para com a comunidade.

Portanto, pela sua composição, o plano de formação também apresenta características de um plano de ação, pois traz os temas a serem desenvolvidos, atividades previstas, atores sociais envolvidos e as finalidades que orientam a missão educativa de um CEFFA (SILVA, 2011). Nessa perspectiva, o desdobramento das atividades envolve constantemente um processo caracterizado, principalmente, pela interação verbal, a qual se desenvolve de duas maneiras: (i) face a face, isto é, quando os estudantes, monitores, pais e outros atores da comunidade interagem oralmente com a mediação da leitura ou da escrita, como, por exemplo, abordar/discutir o tema de um PE com o parceiro, produzir os textos do gênero caderno da realidade ${ }^{12}$ com a colaboração de alguém, etc.; (ii) a distância, por

12- Para maiores detalhes acerca desse gênero, consultar Silva $(2011,2018)$ e Silva, Andrade e Moreira (2015). 
exemplo, quando o autor-leitor ou leitor-autor (estudante) escreve a síntese do PE no caderno da realidade ou lê as notas de uma entrevista realizada com um ator social da comunidade a respeito do tema de um PE para elaborar textos nesse caderno. Além disso, o plano de formação se configura como um tipo de estratégia assumida pela EFAZD (e demais CEFFA) para regular a proposta didático-pedagógica orientada pelos princípios da PA, favorecendo o controle e os desdobramentos do processo de execução dos PE e de produção do gênero caderno da realidade.

\section{Considerações finais}

Considerando que o objetivo deste trabalho é analisar e compreender o processo de construção e implementação de um plano de formação nas atividades formativas em uma turma do $1^{\circ}$ ano do ensino médio da Escola Família Agrícola Zé de Deus (EFAZD), podemos afirmar que tal plano possibilita que as práticas didático-pedagógicas da escola-campo, orientadas pelos princípios da PA, aconteçam no decorrer do desenvolvimento de estudo de temas geradores dos PE ligados à vida local, comunitária, profissional e ao meio ambiente, já que o objetivo é oferecer ao estudante oriundo do contexto rural uma formação articulada entre atividades dos meios profissional, social, político e econômico. Além da interação com o monitor (professor formador), ao longo da implementação dos temas dos PE, os estudantes também interagem com outros atores sociais da comunidade local.

Ademais, ressaltamos que o diálogo estabelecido na alternância por meio dos temas dos planos de estudo e das atividades do tempo escola e do tempo comunidade promove mudanças no componente curricular do CEFFA, uma vez que os temas geradores (PE) elencados no plano de formação estão vinculados diretamente às atividades do meio rural e da realidade socioprofissional do jovem camponês. Ao propor aos estudantes e aos monitores que desenvolvessem tais temas, percebemos em nossa pesquisa que a Escola Família Agrícola pesquisada sinaliza em seu projeto político-pedagógico uma conexão dos conteúdos com a realidade das famílias camponesas, das comunidades, do próprio CEFFA e dos seus atores sociais. Isso, evidentemente, gera uma ruptura com o currículo engessado da escola rural, além de concretizar a proposta formativa da educação do campo.

Portanto, nessa relação que se estabelece, depreendemos que há uma articulação com a realidade do contexto do campo e com a comunidade local, favorecendo a compreensão das contradições e dos problemas existentes de natureza educacional, social, ambiental, científica, econômica, política e ideológica, os quais estão presentes no cotidiano dos camponeses. Ademais, são desenvolvidas atividades significativas que contemplam práticas orais e escritas (escola, família, comunidade), as quais valorizam e promovem o letramento dos estudantes (SILVA, 2018).

\section{Referências}

ANDRÉ, Marly Eliza Dalmazo Afonso de. Etnografia da prática escolar. 18. ed. Campinas: Papirus, 2012.

ANGROSINO, Michael. Etnografia e observação participante. Porto Alegre: Artmed: Bookman, 2009. 
ARROYO, Miguel Gonzalez. Currículo, território em disputa. Petrópolis: Vozes, 2013.

CALDART, Roseli Salete. Por uma educação do campo: traços de uma identidade em construção. In: KOLLING, Edgar Jorge; CERIOLE, Paulo Ricardo; CALDART, Roseli Salete (Org.). Educação do campo: identidade e políticas públicas. Brasília: Articulação Nacional por uma Educação do Campo, 2002. p. 18-25.

CALIARI, Rogério. A presença da família camponesa na escola família agrícola: 0 caso de Olivânia. 2013. 563f. Tese (Doutorado em Educação) - Universidade Federal do Espírito Santo, Vitória, 2013.

COLINAS. Projeto pedagógico da Escola Municipal Família Agrícola Zé de Deus de Colinas do Tocantins-TO. Colinas do Tocantins: [s. n.], 2015. Mimeo.

DENZIN, Norman Kent; LINCOLN, Yvonna Sessions. Introdução: a disciplina e a prática da pesquisa qualitativa. In: DENZIN, Norman Kent; LINCOLN, Yvonna Sesseions. 0 planejamento da pesquisa qualitativa: teorias e abordagens. 2. ed. Porto Alegre: Artmed: Bookman, 2006. p. 15-41.

ESTEVAM, Dimas de Oliveira. Casa Familiar Rural: a formação com base na pedagogia da alternância. 2001. 181f. Dissertação (Mestrado em Administração) - Universidade Federal de Santa Catarina, Florianópolis, 2001.

FREIRE, Paulo. Pedagogia do oprimido. 48. reimp. Rio de Janeiro: Paz e Terra, 2005.

GARCIA-MARIRRODRIGA, Roberto; PUIG-CALVÓ, Pedro. Formação em alternância e desenvolvimento local: o movimento educativo dos CEFFA no mundo. Belo Horizonte: 0 Lutador, 2010.

GIMONET, Jean-Claude. Praticar e compreender a pedagogia da alternância dos CEFFAs. Petrópolis: Vozes; Paris: AIMFR, 2007.

KLEIMAN, Angela Bustos. Letramento na contemporaneidade. Bakhtiniana, São Paulo, v. 9, n. 2, p. 72-91, 2014.

KLEIMAN, Angela Bustos; SANTOS, Cosme Batista dos. Estudos de letramento do professor: percursos metodológicos. In: GONÇALVES, Adair Vieira; SILVA, Wagner Rodrigues; GÓIS, Marcos Lúcio de Sousa (Org.). Visibilizar a linguística aplicada: abordagens teóricas e metodológicas. Campinas: Pontes, 2014. p. 183-204.

MASON, Jennifer. Qualitative researching. 2. ed. London: Sage, 2002.

MATTOS, Luciane Maria Serrer de. 0 plano de formação no contexto da pedagogia da alternância: articulações entre temas geradores e conteúdos do ensino médio na Casa Familiar Rural de Cruz Machado-PR. 2014. 119f. Dissertação (Mestrado em Desenvolvimento Regional) - Universidade Tecnológica Federal do Paraná, Pato Branco, 2014.

MOITA LOPES, Luiz Paulo da. Uma linguística aplicada mestiça e ideológica: interrogando o campo como linguista aplicado. In: MOITA LOPES, Luiz Paulo da (Org.). Por uma linguística aplicada indisciplinar. São Paulo: Parábola, 2006. p. 13-44.

MOREIRA, Flavio. Formação e práxis dos professores em escolas comunitárias rurais: por uma pedagogia da alternância. 2000. 248f. Dissertação (Mestrado em Educação) - Universidade Federal do Espírito Santo, Vitória, 2000. 
NOSELLA, Paolo. Origens da pedagogia da alternância no Brasil. Vitória: Edufes, 2014.

QUEIR0Z, João Batista Pereira de. Construção das Escolas Família Agrícolas no Brasil: ensino médio e educação profissional. 2004. 211f. Tese (Doutorado em Sociologia) - Universidade de Brasília, Brasília, 2004.

RIBEIRO, Marlene. Pedagogia da alternância na educação rural/do campo: projetos em disputa. Educação e Pesquisa, São Paulo, v. 34, n. 1, p. 27-45, jan./abr. 2008. D0l: http://dx.doi.org/10.1590/S151797022008000100003

SILVA, Cícero da. Pedagogia da alternância: práticas de letramentos em uma Escola Família Agrícola brasileira. 2018. 232f. Tese (Doutorado em Letras: Ensino de Língua e Literatura) - Universidade Federal do Tocantins, Araguaína, 2018.

SILVA, Cícero da. Pedagogia da alternância: um estudo do gênero Caderno da Realidade com foco na retextualização. 2011. 149f. Dissertação (Mestrado em Letras: Ensino de Língua e Literatura) - Universidade Federal do Tocantins, Araguaína, 2011.

SILVA, Cícero da; ANDRADE, Karylleila dos Santos; MOREIRA, Flavio. A retextualização no gênero Caderno da Realidade na pedagogia da alternância. Acta Scientiarum. Language and Culture, Maringá, v. 37, n. 4, p. 359-369, out./dez. 2015. DOl: http://dx.doi.org/10.4025/actascilangcult.v37i4.25050

SILVA, Cícero da; GONÇALVES, Adair Vieira. A etnografia e suas contribuições para o desenvolvimento de uma pesquisa no contexto de ensino da pedagogia da alternância. Trabalhos em Linguística Aplicada, Campinas, v. 57 , n. 1, p. 551-578, jan./abr. 2018. DOl: http://dx.doi.org/10.1590/010318138651040333151

SILVA, Lourdes Helena da. As experiências de formação de jovens do campo: alternância ou alternâncias? Curitiba: CRV, 2012 [2003].

STREET, Brian Vincent. Letramentos sociais: abordagens críticas do letramento no desenvolvimento, na etnografia e na educação. Tradução de Marcos Bagno. São Paulo: Parábola, 2014.

TINOCO, Glícia Marili Azevedo de Medeiros. Projetos de letramento: ação e formação de professores de língua materna. 2008. 254f. Tese (Doutorado em Linguística Aplicada) - Universidade Estadual de Campinas, Campinas, 2008.

Recebido em: 29.01.2019

Revisado em: 20.07.2019

Aprovado em: 14.08.2019

Cícero da Silva é doutor em letras pela Universidade Federal do Tocantins e professor da mesma instituição. Atua nas áreas de Linguística Aplicada e Educação do Campo/Pedagogia da Alternância. Lidera 0 Grupo de Estudos e Pesquisas em Educação do Campo - Gepec/CNPq. 


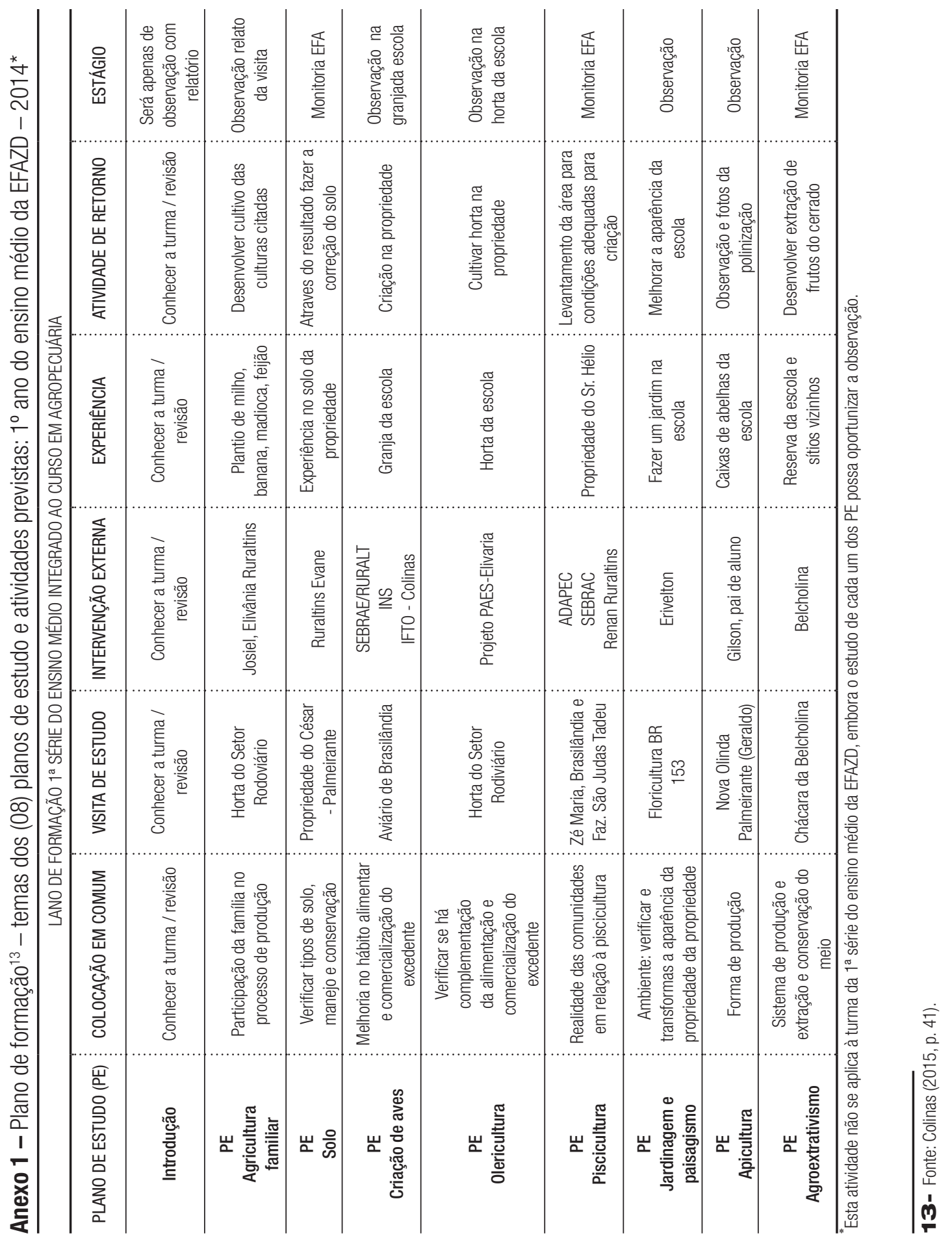

